\title{
Vulnerability of the L5 nerve root during anterior lumbar interbody fusion at L5-S1: case series and review of the literature
}

\author{
Ehsan Dowlati, MD, ${ }^{1}$ Hepzibha Alexander, MD, ${ }^{2}$ and Jean-Marc Voyadzis, MD'1 \\ 1Department of Neurosurgery, MedStar Georgetown University Hospital; and ${ }^{2}$ Georgetown University School of Medicine, \\ Washington, DC
}

\begin{abstract}
OBJECTIVE Nerve root injuries associated with anterior lumbar interbody fusion (ALIF) are uncommonly reported in the literature. This case series and review aims to describe the etiology of L5 nerve root injury following ALIF at L5-S1.

METHODS The authors performed a single-center retrospective review of prospectively collected data of patients who underwent surgery between 2017 and 2019 who had postoperative L5 nerve root injuries after stand-alone L5-S1 ALIF. They also reviewed the literature with regard to nerve root injuries after ALIF procedures.
\end{abstract}

RESULTS The authors report on 3 patients with postoperative L5 radiculopathy. All 3 patients had pain that improved. Two of the 3 patients had a neurological deficit, one of which improved.

CONCLUSIONS Stretch neuropraxia from overdistraction is an important cause of postoperative L5 radiculopathy after L5-S1 ALIF. Judicious use of implants and careful preoperative planning to determine optimal implant sizes are paramount.

https://thejns.org/doi/abs/10.3171/2020.6.FOCUS20315

KEYWORDS anterior lumbar; interbody fusion; L5-S1; L5 nerve root; complications; neuropraxia; spinal fusion

$\mathrm{A}$ NTERIOR lumbar interbody fusion (ALIF) is an effective surgical technique for the treatment of a wide range of pathologies of the lumbosacral spine. Evolution in surgical technique, approach, cage design, and biological implants has enhanced its safety profile and expanded the clinical utility since its introduction in the early 1930s. ${ }^{1,2}$ ALIF is currently the second most common method of spinal fusion performed in patients with degenerative disc disease (DDD), herniated nucleus pulposus, or back pain. ${ }^{3}$ Clinical and radiological outcomes are particularly favorable for DDD, spondylolisthesis, and failed posterior fusion. ${ }^{4}$

The adoption of ALIF in degenerative disorders can be attributed to the unique advantages conferred by the anterior approach and its ideal application to the L5-S1 level. The bifurcation of the aorta and vena cava above this level provides direct and unobstructed access to the anterior disc space at L5-S1, resulting in a wide working corridor. This is in contrast to posterior and lateral approaches, where access is limited by bony, ligamentous, or muscular structures. The efficient access allows for a comprehensive discectomy, increased distraction, foraminal decompression, and deformity correction, including restoration of lumbar lordosis, reduction of anterolisthesis, and achievement of coronal and sagittal balance. ${ }^{5-12}$ ALIF restores foraminal height, local disc angle, and lordosis better than transforaminal lumbar interbody fusion. ${ }^{13}$ Fusion potential is also enhanced due to the larger surface area that is in contact with the graft..$^{814-17}$ Other reported benefits include reduced blood loss, short operating times, and reduced hospital stay. ${ }^{8,18-21}$

Despite the clear benefits, ALIF is not without associated risks. The proximity of the anterior spinal column to major blood vessels places them at significant risk of iatrogenic injury. Venous injuries are the predominant complication, with deep venous thrombosis occurring in $2 \%-11 \%$ of patients. Damage to the sympathetic (superior hypogastric) plexus can result in leg and groin dysesthesias as well

ABBREVIATIONS ALIF = anterior lumbar interbody fusion; $\mathrm{AP}=$ anteroposterior; $\mathrm{DDD}=$ degenerative disc disease; $\mathrm{EMG}=$ electromyography; $\mathrm{NCS}=$ nerve conduction study; SSEP = somatosensory evoked potential.

SUBMITTED April 15, 2020. ACCEPTED June 9, 2020.

INCLUDE WHEN CITING DOI: 10.3171/2020.6.FOCUS20315. 

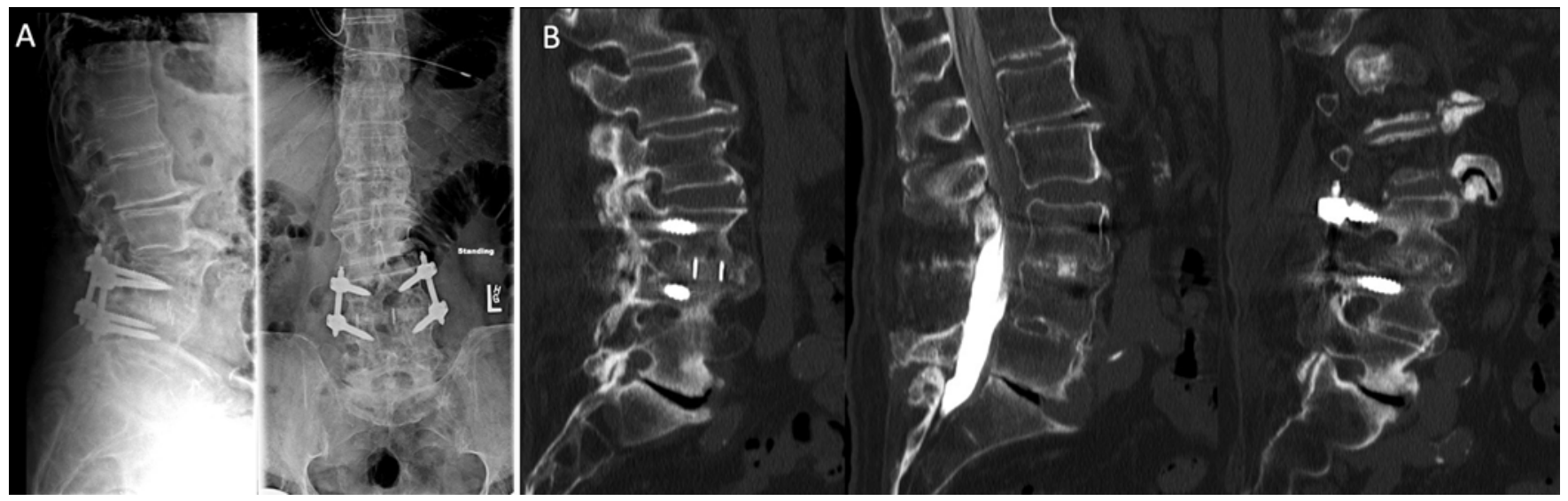

FIG. 1. Case 1, preoperative imaging. A: Lateral (left) and AP (right) radiographs of the lumbar spine. B: Lumbar CT myelograms showing severe disc degeneration at L5-S1, loss of disc height, and vacuum disc phenomenon. There is no evidence of canal stenosis.

as retrograde ejaculation $(1 \%-4.3 \%))^{22-24}$ Visceral complications include postoperative ileus, hernia, and bowel perforation. Prosthesis-related injuries such as graft migration or subsidence and infection represent $1 \%$ and $2 \%$ of complications, respectively. Nerve root injuries, while more prevalent in the posterior and lateral approaches, are scarcely reported in the anterior approach due to sparing of neural elements. ${ }^{25}$ Paresthesias and weakness are more common in lateral lumbar interbody fusion and vary widely in frequency $(0.7 \%-30 \%$ and $3.4 \%-23.7 \%$, respectively). ${ }^{26-33}$

We conducted a retrospective review of all L5-S1 ALIF procedures performed at our institution between 2017 and 2019 specifically evaluating for nerve root injury. We present the cases of 3 patients with postoperative L5 nerve root injuries. An explanation of the anatomical basis of this injury based on current literature and recommendations to mitigate this complication are discussed.

\section{Summary of Cases}

A total of 352 ALIF procedures were performed at our institution from 2017 to 2019. Of the 352 procedures, 111 were stand-alone ALIFs at L5-S1 with no posterior instrumentation or fusion. Seven patients within this cohort were identified as having experienced symptomatic nerve root injuries within 60 days of surgery. Two patients had cage subsidence causing nerve impingement. One patient developed osteodiscitis leading to radiculopathy. The other 4 patients developed L5 nerve root injuries without obvious etiology. Three of these cases for which preoperative and postoperative imaging was available are illustrated here.

\section{Case 1}

An 80-year-old man presented with complaints of progressive lumbosacral pain accompanied by radiation to the lateral calves and buttocks along with hip pain and stiffness. The pain was severe and occurred daily and significantly limited his ability to stand or walk for extended periods. The patient's past medical history was significant for extensive cardiac disorders and bilateral hip replacements. His past surgical history was also notable for a prior multilevel laminectomy and L3-4 fusion and extensive spondylotic disease with large bridging osteophytes from the thoracic spine to L5. On examination, motor strength and sensation were intact and symmetric in the bilateral lower extremities. Imaging studies, including CT myelography and dynamic radiography, revealed multilevel ankylosis throughout the lumbar spine with large bridging osteophytes from the thoracic spine to L5, severe disc degeneration at L5-S1, loss of disc height, and vacuum disc phenomenon (Fig. 1).

The patient underwent many sessions of physical therapy and steroid injections without relief. He was admitted to the hospital with intractable back pain and an inability to walk. He underwent a stand-alone ALIF at L5-S1 (Sovereign, Medtronic). A large implant was placed, with dimensions of $42 \mathrm{~mm}$ in width and $16 \mathrm{~mm}$ in height with $12^{\circ}$ of lordosis (Table 1). A right-sided approach was utilized given the patient's history of a sole kidney on the left side. Postoperatively, his back pain resolved; however, he developed new right hip and lateral thigh pain along with weakness in dorsiflexion. On examination, his motor strength had decreased to $4+/ 5$ in the quadriceps, $3 / 5$ in tibialis anterior, and $2 / 5$ in extensor hallucis longus muscles in the right lower extremity. Sensation remained intact. Postoperative CT scanning of the lumbar spine revealed an intact appearance of the instrumentation without evidence of canal or foraminal compromise and an increased disc height at L5-S1 (Fig. 2). MRI could not be performed due to the presence of a cardiac pacemaker. At 3 months postoperatively, the patient was free of back pain but right dorsiflexion weakness remained. Electromyography (EMG) and nerve conduction studies (NCSs) demonstrated an active and chronic right L5 radiculopathy and mild polyneuropathy.

\section{Case 2}

A 51-year-old woman with a history of right-sided L4-5 discectomy and obesity presented with diffuse, bilateral pain in the lumbosacral region. The back pain radi- 
TABLE 1. Implant sizes and comparison of preoperative and postoperative disc and foraminal height restoration

\begin{tabular}{|c|c|c|c|c|c|c|c|c|c|c|c|c|}
\hline & \multicolumn{3}{|c|}{ Implant Size } & \multicolumn{3}{|c|}{ Anterior Disc Height } & \multicolumn{3}{|c|}{ Posterior Disc Height } & \multicolumn{3}{|c|}{ L5 Foraminal Height } \\
\hline & $\begin{array}{l}\text { Height } \\
(\mathrm{mm})\end{array}$ & $\begin{array}{l}\text { Width } \\
(\mathrm{mm})\end{array}$ & $\begin{array}{l}\text { Lordosis } \\
\left({ }^{\circ}\right)\end{array}$ & $\begin{array}{c}\text { Preop } \\
(\mathrm{mm})\end{array}$ & $\begin{array}{l}\text { Postop } \\
\text { (mm) }\end{array}$ & Increase & $\begin{array}{l}\text { Preop } \\
(\mathrm{mm})\end{array}$ & $\begin{array}{l}\text { Postop } \\
\text { (mm) }\end{array}$ & Increase & $\begin{array}{l}\text { Preop } \\
(\mathrm{mm})\end{array}$ & $\begin{array}{l}\text { Postop } \\
\text { (mm) }\end{array}$ & Increase \\
\hline \multicolumn{13}{|l|}{ Case no. } \\
\hline 1 & 16 & 42 & 12 & 7.5 & 18.8 & $150 \%$ & 5.0 & 9.8 & $96 \%$ & 13.9 & 22.1 & $59 \%$ \\
\hline 2 & 13 & 36 & 12 & 7.2 & 14.9 & $107 \%$ & 4.8 & 9.1 & $90 \%$ & 14.2 & 20.1 & $42 \%$ \\
\hline 3 & 16 & 42 & 8 & 5.8 & 14.3 & $147 \%$ & 4.5 & 8.6 & $91 \%$ & 12.9 & 19.3 & $50 \%$ \\
\hline Mean for study cases & 15 & 40 & 10.7 & 7.0 & 16.0 & $134 \%$ & 4.8 & 9.2 & $92 \%$ & 13.7 & 20.4 & $49 \%$ \\
\hline Mean for 10 cases w/ no L5 injury & 14.1 & 36.4 & 12.6 & 9.5 & 19.4 & $105 \%$ & 5.8 & 10.1 & $78 \%$ & 13.4 & 18.2 & $40 \%$ \\
\hline
\end{tabular}

ated into the buttocks and posterior aspect of the leg down to the ankle and was refractory to conservative measures over a period of 18 months. On examination, gross motor strength was diminished $(4+/ 5)$ in the right anterior tibialis muscle but was otherwise intact. Sensation was symmetric and equal bilaterally. Reflexes were normal. The patient's gait was narrow based. MRI of the lumbar spine showed significant disc degeneration at L5-S1 with associated loss of disc height and endplate changes. Right laminotomy changes were present at L4-5 with mild disc desiccation at L4-5. Her symptoms were refractory to conservative measures.

The patient underwent a stand-alone ALIF at L5-S1 (Centinel Spine). A medium-sized implant was placed, with dimensions of $36 \mathrm{~mm}$ in width and $13 \mathrm{~mm}$ in height anteriorly with $12^{\circ}$ of lordosis (Table 1). Postoperatively, she developed new left leg pain and weakness and numbness along the L5 distribution. Physical examination revealed weakness in the left tibialis anterior and extensor hallucis longus (3/5) muscles and a positive straight
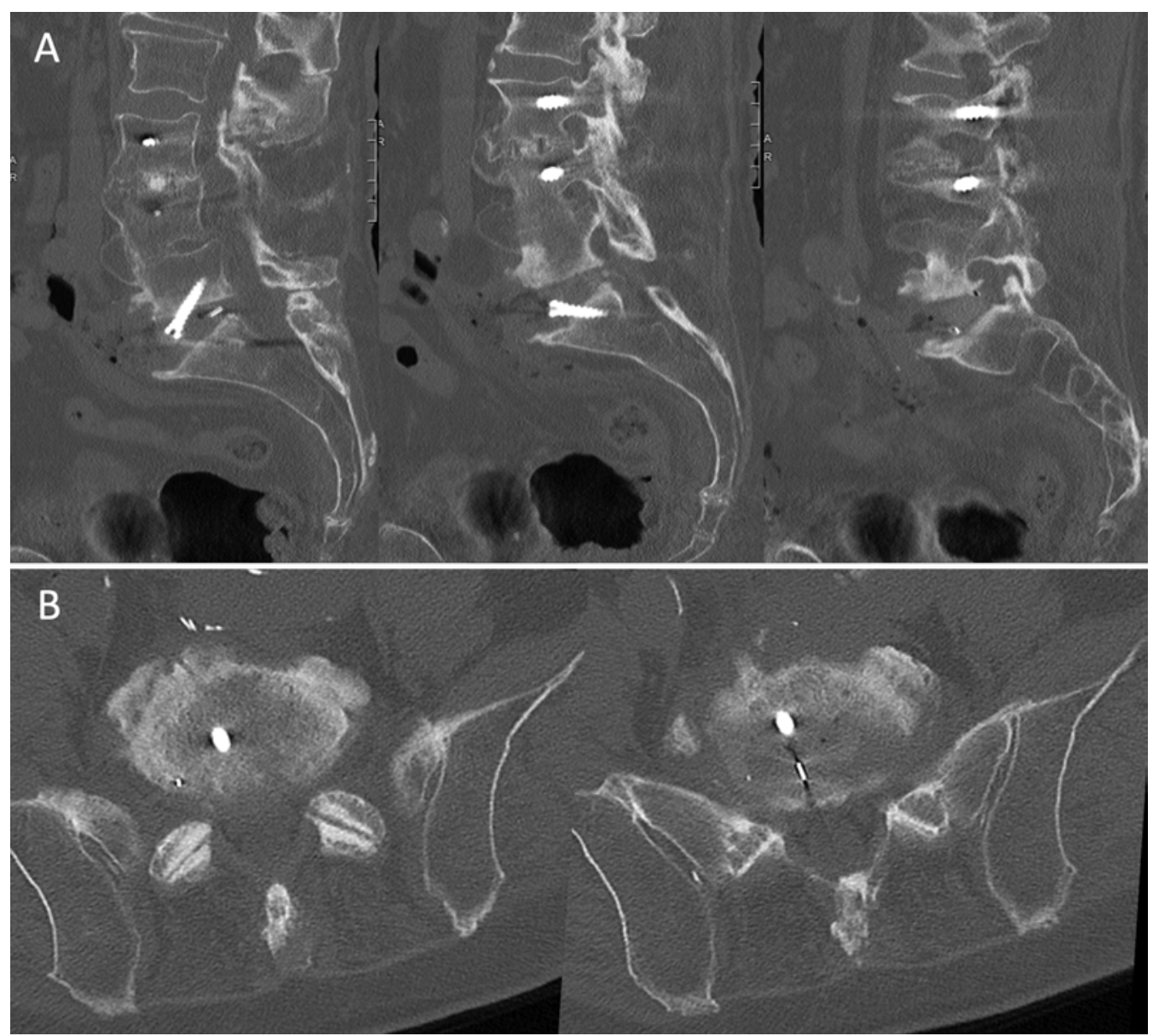

FIG. 2. Case 1, postoperative imaging. Sagittal (A) and axial (B) CT scans of the lumbar spine, revealing increased disc space height and postsurgical changes without central canal or foraminal stenosis at L5-S1. 

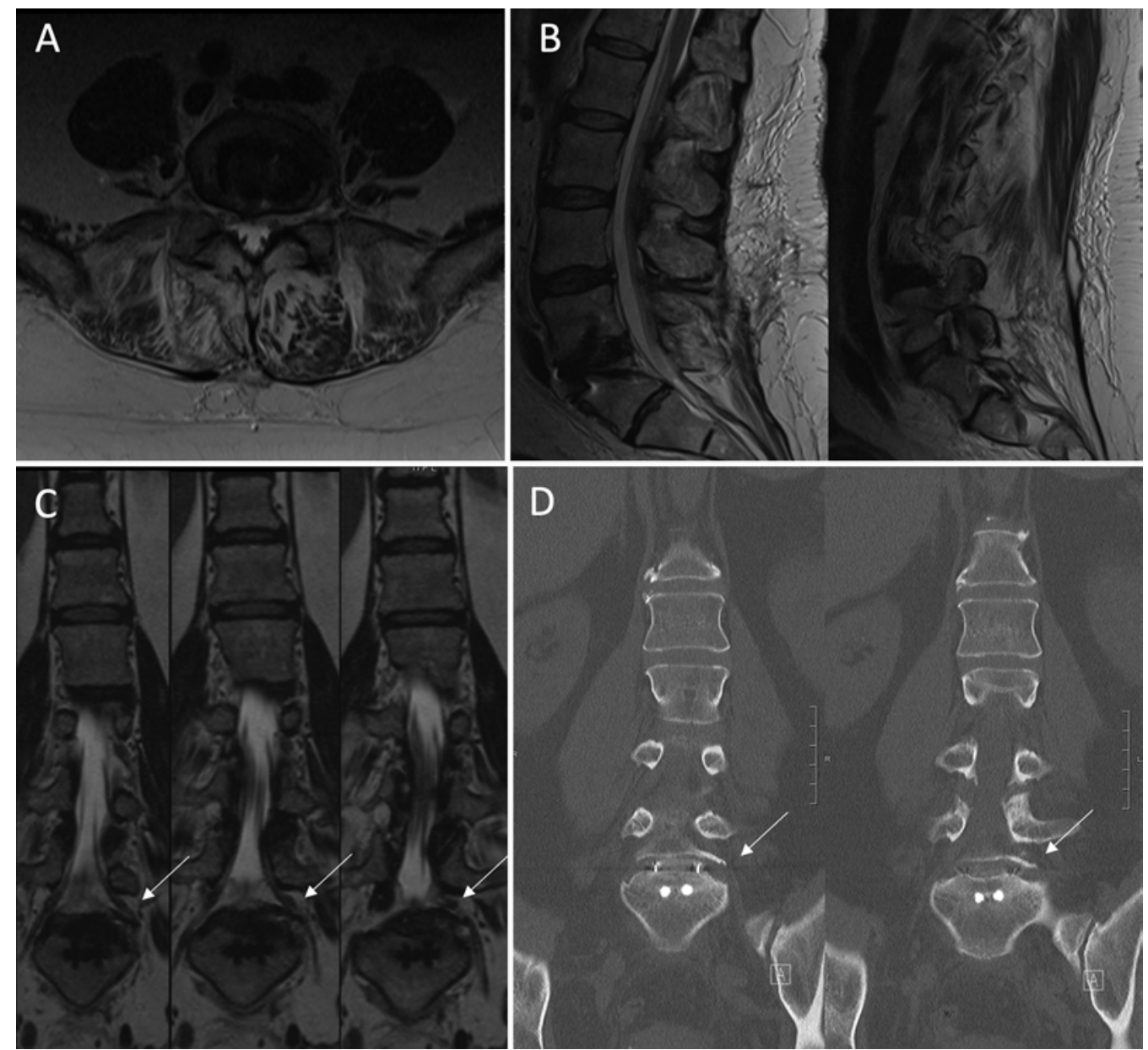

FIG. 3. Case 2, postoperative imaging. A and B: Axial (A) and sagittal (B) T2-weighted MR images showing no obvious stenosis. $C$ and D: Coronal MR images (C) and CT scans (D) of the lumbar spine, showing posteroinferior osteophyte complex causing possible impingement and stretch on the left $L 5$ exiting nerve root. Note the sharper angle the nerve root takes against the complex on the left (arrows) compared with the right nerve root.

leg-raising test on the left. Postoperative MRI and CT revealed an intact appearance of the graft and instrumentation without obvious compromise of the L5-S1 foramen or lateral recess at L4-5 (Fig. 3A and B). The coronal reconstructions revealed possible displacement of the left L5 nerve against a posteroinferior osteophyte at L5-S1 due to disc height reexpansion (Fig. 3C and D). The patient's symptoms persisted despite various medications, including dexamethasone and gabapentin-later switched to pregabalin. A left L5 selective nerve block administered on postoperative day 5 provided some symptom relief. The patient was discharged on postoperative day 6 with a steroid taper. Unfortunately, she was readmitted due to worsening pain. A left L5-S1 extraforaminal far-lateral discectomy and left L4-5 laminotomy, medial facetectomy, and foraminotomy for decompression of the L5 nerve root were performed 15 days after her ALIF surgery, resulting in improvement of her symptoms. She was discharged on postoperative day 3 .

At her 3-month follow-up, the patient continued to have left leg pain, primarily below the knees, accompanied by a feeling of heaviness on ambulation. Her strength remained stable with weakness in the left lower-extremity quadriceps (4/5), tibialis anterior (3/5), and gastrocnemius (4+/5) muscles. She underwent additional CT and MRI of the lumbar spine, which were unrevealing. She was referred for EMG and NCSs; however, she was unable to tolerate the study due to allodynia. At the 6-month follow-up, her pain symptoms had resolved with some improvement in leg weakness. She continued to take gabapentin and was followed by a pain specialist. She also had weakness in knee extension and dorsiflexion on the left (4/5) but was able to ambulate better. At the 1-year follow-up, the patient was off all pain medications and experiencing no pain other than occasional paresthesias of the left foot and improved dorsiflexion strength.

\section{Case 3}

A 69-year-old woman with a prior history of L4-5 fusion presented with constant, severe low-back and right leg pain with associated numbness and tingling along the right lateral thigh that was refractory to conservative measures. Her neurological examination findings were normal. Anteroposterior (AP) and lateral radiographs of the lum- 

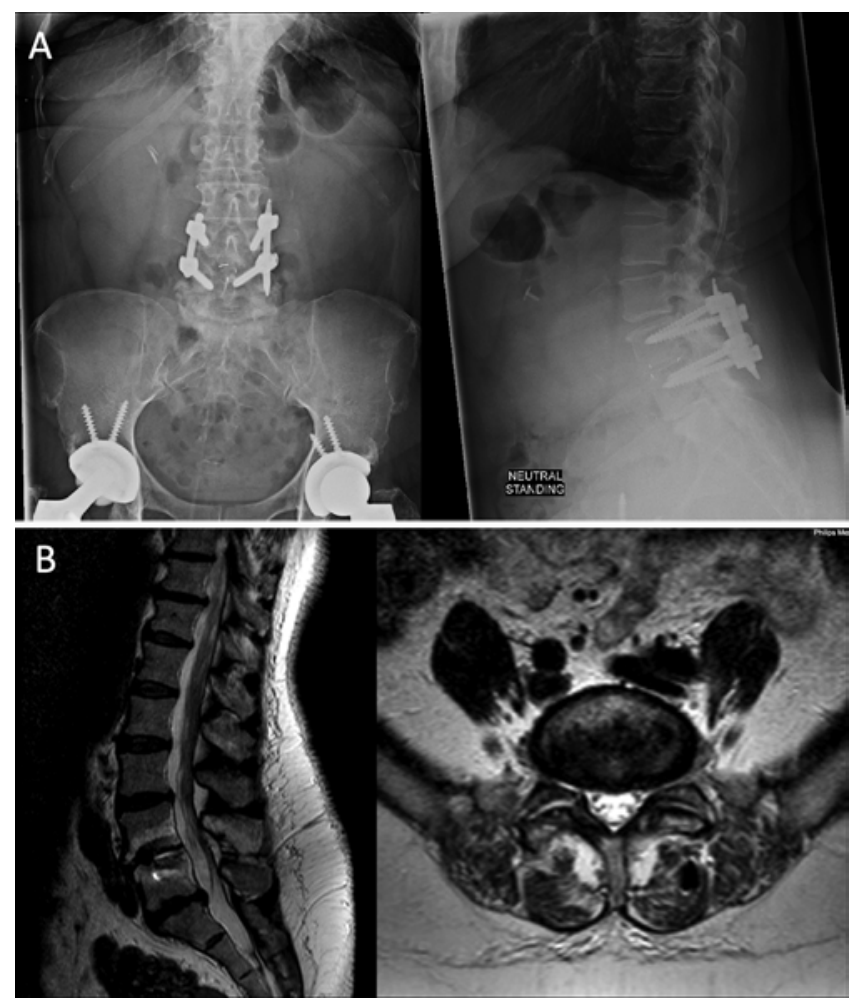

FIG. 4. Case 3, preoperative imaging. A: AP (left) and lateral (right) radiographs of the lumbar spine, demonstrating previous instrumented fusion at L4-5 and significant adjacent-segment disc degeneration at L5-S1. B: Sagittal (left) and axial (right) MR images showing DDD and foraminal stenosis at L5-S1.

bar spine revealed significant adjacent disc degeneration and spondylosis at L5-S1 (Fig. 4A). Flexion-extension radiographs did not demonstrate any dynamic instability. MRI of the lumbar spine revealed significant adjacent disc degeneration and spondylosis at L5-S1 with a broad disc protrusion causing foraminal stenosis (Fig. 4B). The patient underwent an L5-S1 ALIF (Sovereign). A large implant was placed, with dimensions of $42 \mathrm{~mm}$ in width anteriorly and $16 \mathrm{~mm}$ in height with $8^{\circ}$ of lordosis (Table 1). Her postoperative course was uneventful. Postoperative AP and lateral radiographs of the lumbar spine demonstrated normal alignment, increased disc space height at L5-S1, and expected postsurgical changes (Fig. 5). She was discharged home 3 days after surgery.

Six weeks after surgery, the patient experienced increasing pain in the right leg in an L5 distribution despite various medications. Her neurological examination findings, however, remained unchanged from baseline. A radiograph of the lumbar spine did not show any evidence of hardware failure or instability. MRI revealed right-sided foraminal stenosis resulting from paracentral placement of the L5-S1 intervertebral device and significant reexpansion of disc height at the L5-S1 level. A right-sided L5 laminectomy, complete facetectomy, and foraminotomy for decompression of the right L5 root were performed 3 months after the index surgery with substantial improvement in symptoms. EMG and NCSs were not offered in the absence of neurological impairment.

\section{Discussion}

The superiority of ALIF in maximizing disc height, both anteriorly and posteriorly, is well established. Substantial increases in postoperative disc height ranging from 8.7 to $15.9 \mathrm{~mm}$ with increases up to $70 \%$ have been reported, along with increases in foraminal height of up to $33 \% .^{34-36}$ This has been associated with improved pain and functional outcomes as evidenced by improvements in postoperative visual analog scale and Oswestry Disability Index scores. ${ }^{5,6}$

Significant disc height and foraminal height restoration may put the exiting L5 nerve root at risk of injury, leading to neuropraxia. A review of the literature on neurological complications associated with ALIF demonstrates limited data on this topic. The available studies focus on approach and implant-related complications of ALIF, which are much more common than neurological complications. If reported, neurological complications are found in retrospective reviews or meta-analyses and pertain to sympathetic plexus injuries or are presented as single case reports. A prospective analysis on the efficacy and safety of short-stay Enhanced Recovery After Surgery ALIF in treatment of single-level DDD reported transient postoperative radiculopathy in 1 of 44 patients. However, the underlying mechanism for this deficit was not explained or explored. ${ }^{37}$ A case series of 2 patients by Saini et al. demonstrated S1 radiculopathy after L5S1 ALIF with stand-alone constructs. The culprit in both cases was identified as nerve root impingement due to a protruding screw tip. ${ }^{38}$ A retrospective review of 269 patients who underwent lateral lumbar interbody fusion or ALIF treatment revealed transient, postoperative sensory deficits characterized by anterior thigh numbness in 5 patients $(9.6 \%)$. Two patients $(3.8 \%)$ who underwent L5-S1 ALIF experienced foot weakness that presented in the immediate postoperative period and resolved with physical therapy over 3 months. ${ }^{39}$

A review of iatrogenic neurological deficits after lumbar spine surgery showed that the prevalence of anterior approaches ranged from $1.5 \%$ to $5.6 \%$. In this cohort, the average reported neurological complication rate was 9\% (range $0.46-24 \%$ ). Of 731 patients, 30 (4.1\%) demonstrated a new-onset neurological injury after ALIF. ${ }^{40}$ A meta-analysis of 76 papers on anterior lumbar surgery from 2004 to 2015 highlighted the importance of paying close attention to the lumbosacral plexus during exposure and retractor placement with the use of neurophysiological monitoring as a means of preventing inadvertent injury to nerve roots during graft or implant insertion. ${ }^{27}$ Taylor et al. noted that postoperative radiography was inadequate for predicting foraminal violation. They recommended the use of intraoperative EMG for safe placement of interbody devices. ${ }^{41}$ An analysis of failed ALIF due to incomplete foraminal decompression showed that 13 of 223 consecutive cases led to "unfavorable neurologic results." Significant risk factors were L5-S1 level (8.3\% vs $2.9 \%)$, higher body mass index (27 vs $24 \mathrm{~kg} / \mathrm{m}^{2}$ ), and grade facet arthropathy, which limits the ability to restore foraminal size and lordosis. ${ }^{42}$

The significance of postoperative nerve root injury and its underlying etiology was highlighted in a recent ab- 

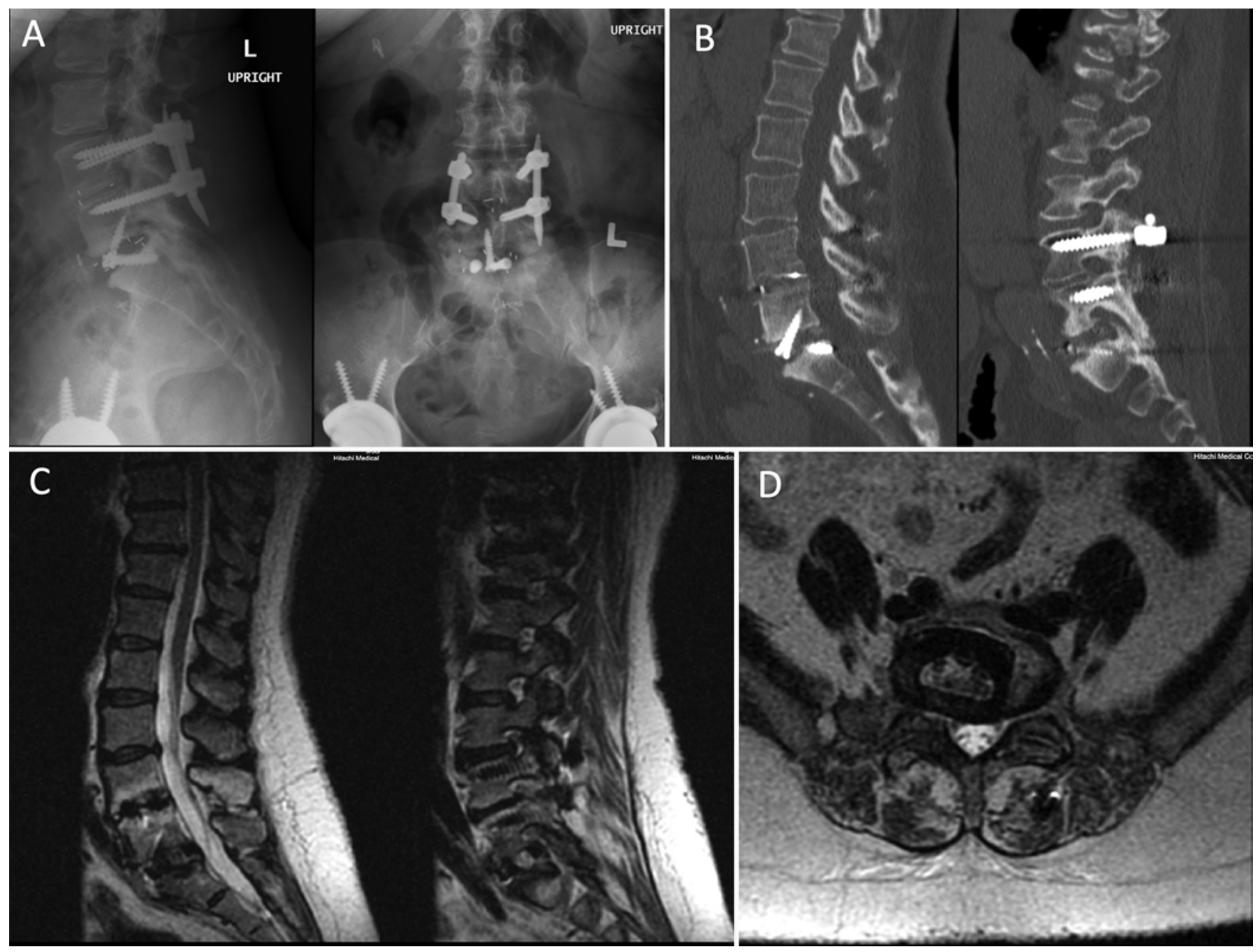

FIG. 5. Case 3, postoperative imaging. A: AP (right) and lateral (left) radiographs obtained on postoperative day 1, demonstrating hardware placement and alignment. B: Sagittal CT images showing increased disc and foraminal height. C and D: Sagittal (C) and axial (D) T2-weighted MR images obtained 6 weeks after index surgery, revealing right-sided foraminal stenosis caused by paracentral placement of the intervertebral device at the L5-S1 level.

stract at the North American Spine Society conference by Dickerman et al. ${ }^{43}$ The authors performed a retrospective review of a prospective population of 67 patients randomized to either ALIF or artificial disc implantation. Patients with postoperative neuropraxia after undergoing either procedure were compared with asymptomatic patients for differences in disc height and lateralization of the interbody device. Postoperative disc heights were significantly elevated in the neuropraxia group. However, there was no association between the laterality of the implant and neuropraxia. The authors concluded that nerve root stretch secondary to overdistraction was the underlying etiology for the neuropraxia and recommended aiming toward the average of normal disc space heights above and below the affected level to minimize the risk of stretch neuropraxia from overdistraction.

A review of our own institution's 111 cases of standalone ALIF at L5-S1 over a 3-year span (2017-2019) resulted in 4 cases (rate of 3.6\%), including the 3 cases discussed here, of postoperative radiculopathy that required intervention and were unexplained by factors such as hardware migration or infection. Specifically, all 4 patients presented with postoperative symptoms consistent with a unilateral L5 nerve radiculopathy and had undergone L5S1 ALIF without posterior instrumentation.

Our patient in case 1 presented some unique challenges. This patient's postoperative course was complicated by new-onset right hip pain, lateral thigh pain, and right foot drop. Imaging did not reveal any obvious pathology. There was no evidence of direct compression resulting in canal or foraminal compromise. Interestingly, the disc height was more than doubled ( $7.5 \mathrm{~mm}$ to $18.8 \mathrm{~mm}$ anteriorly and 5.0 to $9.8 \mathrm{~mm}$ posteriorly; Fig. 6). Table 1 outlines measurements of implant size and disc heights for all cases. A large implant was used due to profound disc degeneration, the large dimensions of the disc space, and concern for instability due to large axial loading forces from the patient's ankylosis of the thoracic and lumbar spine. Three months after the index surgery, his back pain had resolved; however, the foot drop persisted, suggesting an L5 nerve root 


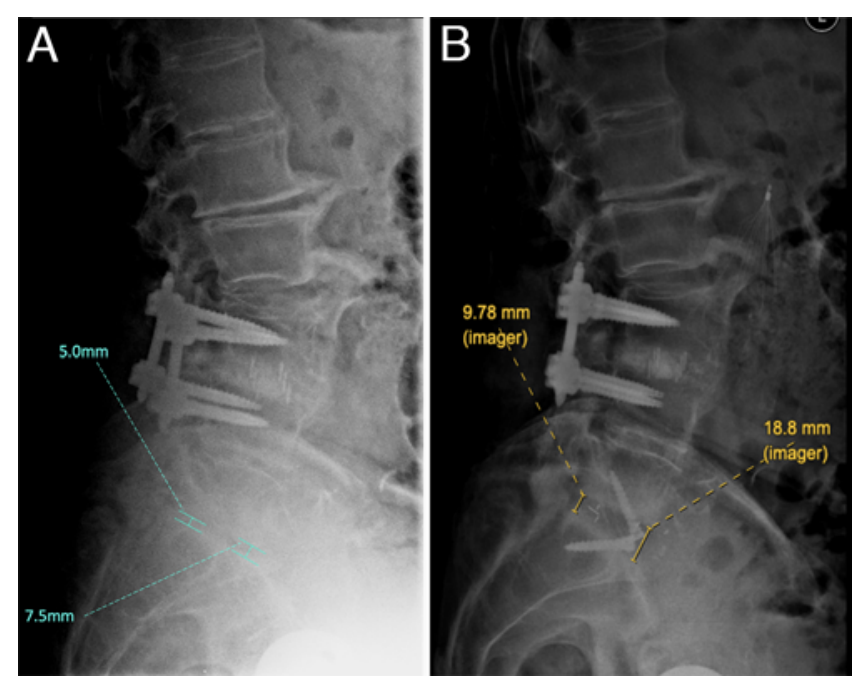

FIG. 6. Case 1. Preoperative (A) and postoperative (B) lateral radiographs showing significant increase in disc height from endplate to endplate with measurements of $7.5 \mathrm{~mm}$ and $5.0 \mathrm{~mm}$ versus $18.8 \mathrm{~mm}$ and $9.78 \mathrm{~mm}$ anteriorly and posteriorly, respectively.

injury confirmed by EMG. A neuropraxia stretch injury was suspected.

In case 2, radicular symptoms were apparent in the immediate postoperative period, and the pain was refractory to several pain management modalities, including selective nerve blocks. Postoperative imaging did not show clear evidence of structural impingement of the L5 nerve root. The coronal reconstructions depicted a possible displacement of the left L5 nerve against a posteroinferior osteophyte at L5-S1 exacerbating a stretch neuropraxia (Fig. 3C and D). This was corroborated during the patient's second surgery, as the nerve root was found to be compressed in the foramen. Overdistraction was, once again, implicated as the culprit given the significant reexpansion in disc height in addition to stretching of the exiting L5 nerve root over a lateral osteophyte complex.

In case 3, symptoms of L5 radiculopathy emerged 6 weeks after the index surgery without any associated change in objective neurological examination findings. MRI identified paracentral implant placement causing right-sided foraminal stenosis at L5-S1. Additionally, a significant increase in anterior and posterior disc heights from 5.8 to 14.3 and 4.5 to $8.6 \mathrm{~mm}$, respectively, was noted. Based on these findings, a combination of large interbody size resulting in excessive distraction and lateral placement of the implant causing direct compression of the L5 nerve root was determined to be the etiology of the neuropraxia. Fortunately, the patient experienced significant improvement in radicular symptoms after a posterior decompression.

The 3 cases presented herein highlight overdistraction as an important cause of L5 nerve root injury after L5S1 ALIF surgery. The anatomical basis of this injury lies in the juxtaposition of the relatively tethered nerve root within a mobile osteoligamentous enclosure. As a result, any changes in spinal canal length place the nerve root at a high risk for stretch, particularly in the lumbosacral region, where nerve roots have a longer intraspinal course within the central and lateral recesses. ${ }^{44}$ While the magnitude of stretch required to cause a nerve root injury has not been established, careful selection of interbody implant size and central placement can mitigate this complication. Utilizing an implant size that equals the average of normal disc space heights above and below the level of the affected region may serve as a guide. ${ }^{43}$ We found an average increase in anterior and posterior disc heights of $134 \%$ and $92 \%$, respectively, and a foraminal height increase of almost 50\% (Table 1). We compared this with 10 other patients in whom stand-alone L5-S1 ALIFs were performed in the same time period without nerve root complications. To be consistent, we performed this analysis on 10 consecutive patients with available pre- and postoperative imaging. We found an average percent increase in anterior and posterior disc heights of $105 \%$ and $78 \%$, respectively, and foraminal height increase of $40 \%$ (Table 1). Although there is an overall trend toward a higher percent increase in disc height, this sample is not enough to make any statistical conclusions. Additionally, we cannot rule out other causes of L5 nerve root injuries with certainty, such as lumbosacral stretch from retractor placement, inadequate foraminal decompression, or iatrogenic injury during discectomy. Given our findings, we recommend that caution be exercised when considering more than doubling the disc height. Technology used to customize implants to fit patient-specific needs and match patient's endplate anatomy is also under investigation and in early use. ${ }^{45}$

In all 3 cases, we did not use EMG or somatosensory evoked potential (SSEP) monitoring during surgery, and it is unclear if neuromonitoring would have detected an abnormality intraoperatively. In addition, in many instances, the loss of SSEP signals may be secondary to vascular ischemia after retractor placement during exposure, which is typically transient. Another potential cause of postoperative neuropraxia would be direct iatrogenic injury to the nerve roots during discectomy or disc preparation, which could be detected by neuromonitoring during the case. A recent retrospective review of intraoperative SSEP monitoring in 189 patients reported alerts in $7.9 \%$ of cases with higher rates in multilevel procedures. No patient in this series had new postoperative neurological deficits. ${ }^{46}$

\section{Conclusions}

The L5 nerve root is vulnerable during ALIF surgery at L5-S1. We have presented 3 cases of L5 nerve root injuries after L5-S1 ALIF. Significant disc height restoration can lead to overdistraction and stretch neuropraxia, with the consequence of permanent neurological injury. Judicious use of implants and careful preoperative planning to determine optimal implant sizes are paramount. Centering implants to avoid foraminal compromise or excessive foraminal height expansion can mitigate the risk. Careful evaluation of postoperative imaging including coronal views might provide valuable information. With the increasing utilization of ALIF, further studies with comparative radiographic analysis aimed at understanding the dynamics of stretch-induced nerve root injury are critical to refine this technique and prevent unwarranted complications. 


\section{References}

1. de Kunder SL, Rijkers K, Caelers IJMH, et al. Lumbar interbody fusion: a historical overview and a future perspective. Spine (Phila Pa 1976). 2018;43(16):1161-1168.

2. Phan K, Mobbs RJ. Evolution of design of interbody cages for anterior lumbar interbody fusion. Orthop Surg. 2016;8(3): 270-277.

3. Pannell WC, Savin DD, Scott TP, et al. Trends in the surgical treatment of lumbar spine disease in the United States. Spine J. 2015;15(8):1719-1727.

4. Rao PJ, Loganathan A, Yeung V, Mobbs RJ. Outcomes of anterior lumbar interbody fusion surgery based on indication: a prospective study. Neurosurgery. 2015;76(1):7-24.

5. Ajiboye RM, Alas H, Mosich GM, et al. Radiographic and clinical outcomes of anterior and transforaminal lumbar interbody fusions: a systematic review and meta-analysis of comparative studies. Clin Spine Surg. 2018;31(4):E230-E238.

6. Giang G, Mobbs R, Phan S, et al. Evaluating outcomes of stand-alone anterior lumbar interbody fusion: a systematic review. World Neurosurg. 2017;104:259-271.

7. Goz V, Weinreb JH, Schwab F, et al. Comparison of complications, costs, and length of stay of three different lumbar interbody fusion techniques: an analysis of the Nationwide Inpatient Sample database. Spine J. 2014;14(9):2019-2027.

8. Kim J-S, Kim D-H, Lee S-H, et al. Comparison study of the instrumented circumferential fusion with instrumented anterior lumbar interbody fusion as a surgical procedure for adult low-grade isthmic spondylolisthesis. World Neurosurg. 2010; 73(5):565-571.

9. Mobbs RJ, Phan K, Malham G, et al. Lumbar interbody fusion: techniques, indications and comparison of interbody fusion options including PLIF, TLIF, MI-TLIF, OLIF/ATP, LLIF and ALIF. J Spine Surg. 2015;1(1):2-18.

10. Pradhan BB, Nassar JA, Delamarter RB, Wang JC. Singlelevel lumbar spine fusion: a comparison of anterior and posterior approaches. J Spinal Disord Tech . 2002;15(5):355-361.

11. Shim JH, Kim WS, Kim JH, et al. Comparison of instrumented posterolateral fusion versus percutaneous pedicle screw fixation combined with anterior lumbar interbody fusion in elderly patients with L5-S1 isthmic spondylolisthesis and foraminal stenosis. J Neurosurg Spine. 2011;15(3):311-319.

12. Teng I, Han J, Phan K, Mobbs R. A meta-analysis comparing ALIF, PLIF, TLIF and LLIF. J Clin Neurosci. 2017;44:11-17.

13. Hsieh PC, Koski TR, O'Shaughnessy BA, et al. Anterior lumbar interbody fusion in comparison with transforaminal lumbar interbody fusion: implications for the restoration of foraminal height, local disc angle, lumbar lordosis, and sagittal balance. J Neurosurg Spine. 2007;7(4):379-386.

14. Behrbalk E, Uri O, Parks RM, et al. Fusion and subsidence rate of stand alone anterior lumbar interbody fusion using PEEK cage with recombinant human bone morphogenetic protein-2. Eur Spine J. 2013;22(12):2869-2875.

15. Lee CS, Hwang CJ, Lee D-H, et al. Fusion rates of instrumented lumbar spinal arthrodesis according to surgical approach: a systematic review of randomized trials. Clin $\mathrm{Or}$ thop Surg. 2011;3(1):39-47.

16. Manzur M, Virk SS, Jivanelli B, et al. The rate of fusion for stand-alone anterior lumbar interbody fusion: a systematic review. Spine J. 2019;19(7):1294-1301.

17. Schroeder GD, Kepler CK, Millhouse PW, et al. L5/S1 fusion rates in degenerative spine surgery: a systematic review comparing ALIF, TLIF, and axial interbody arthrodesis. Clin Spine Surg. 2016;29(4):150-155.

18. Bozzio AE, Johnson CR, Fattor JA, et al. Stand-alone anterior lumbar interbody, transforaminal lumbar interbody, and anterior/posterior fusion: analysis of fusion outcomes and costs. Orthopedics. 2018;41(5):e655-e662.

19. Burke PJ. Anterior lumbar interbody fusion. Radiol Technol. 2001;72(5):423-430.
20. Strube P, Hoff E, Hartwig T, et al. Stand-alone anterior versus anteroposterior lumbar interbody single-level fusion after a mean follow-up of 41 months. J Spinal Disord Tech. 2012; 25(7):362-369.

21. Udby PM, Bech-Azeddine R. Clinical outcome of standalone ALIF compared to posterior instrumentation for degenerative disc disease: a pilot study and a literature review. Clin Neurol Neurosurg. 2015;133:64-69.

22. Carragee EJ, Mitsunaga KA, Hurwitz EL, Scuderi GJ. Retrograde ejaculation after anterior lumbar interbody fusion using rhBMP-2: a cohort controlled study. Spine J. 2011;11(6): 511-516.

23. Inamasu J, Guiot BH. Vascular injury and complication in neurosurgical spine surgery. Acta Neurochir (Wien). 2006; 148(4):375-387.

24. Slosar PJ, Reynolds JB, Schofferman J, et al. Patient satisfaction after circumferential lumbar fusion. Spine (Phila $\mathrm{Pa}$ 1976). 2000;25(6):722-726.

25. Varshneya KB, Medress ZA, Jensen M, et al. Trends in anterior lumbar interbody fusion in the United States: a MarketScan study from 2007 to 2014. Clin Spine Surg. 2020; 33(5):E226-E230.

26. Amaral R, Ferreira R, Marchi L, et al. Stand-alone anterior lumbar interbody fusion-complications and perioperative results. Rev Bras Ortop. 2017;52(5):569-574.

27. Bateman DK, Millhouse PW, Shahi N, et al. Anterior lumbar spine surgery: a systematic review and meta-analysis of associated complications. Spine J. 2015;15(5):1118-1132.

28. Brau SA, Delamarter RB, Schiffman ML, et al. Vascular injury during anterior lumbar surgery. Spine J. 2004;4(4): 409-412.

29. Epstein NE. More nerve root injuries occur with minimally invasive lumbar surgery, especially extreme lateral interbody fusion: a review. Surg Neurol Int. 2016;7(4)(suppl 3):S83S95.

30. Hrabalek L, Adamus M, Wanek T, et al. Surgical complications of the anterior approach to the L5/S1 intervertebral disc. Biomed Pap Med Fac Univ Palacky Olomouc Czech Repub. 2012;156(4):354-358.

31. Quraishi NA, Konig M, Booker SJ, et al. Access related complications in anterior lumbar surgery performed by spinal surgeons. Eur Spine J. 2013;22(suppl 1):S16-S20.

32. Shillingford JN, Laratta JL, Lombardi JM, et al. Complications following single-level interbody fusion procedures: an ACS-NSQIP study. J Spine Surg. 2018;4(1):17-27.

33. Upadhyayula PS, Curtis EI, Yue JK, et al. Anterior versus transforaminal lumbar interbody fusion: perioperative risk factors and 30-day outcomes. Int J Spine Surg. 2018;12(5): $533-542$.

34. Soini J. Lumbar disc space heights after external fixation and anterior interbody fusion: a prospective 2-year follow-up of clinical and radiographic results. J Spinal Disord. 1994;7(6): 487-494.

35. Wang M, Dalal S, Bagaria VB, et al. Changes in the lumbar foramen following anterior interbody fusion with tapered or cylindrical cages. Spine J. 2007;7(5):563-569.

36. Kapustka B, Kiwic G, Chodakowski P, et al. Anterior lumbar interbody fusion (ALIF): biometrical results and own experiences. Neurosurg Rev. 2020;43(2):687-693.

37. Vieli M, Staartjes VE, Eversdjik HAJ, et al. Safety and efficacy of anterior lumbar interbody fusion for discogenic chronic low back pain in a short-stay setting: data from a prospective registry. Cureus. 2019;11(8):e5332.

38. Saini N, Zaidi M, Barry MT, Heary RF. Previously unreported complications associated with integrated cage screws following anterior lumbar interbody fusion: report of 2 cases. J Neurosurg Spine. 2018;28(3):311-316.

39. Januszewski J, Beckman JM, Bach K, et al. Indirect decompression and reduction of lumbar spondylolisthesis does not 
result in higher rates of immediate and long term complications. J Clin Neurosci. 2017;45:218-222.

40. Ghobrial GM, Williams KA Jr, Arnold P, et al. Iatrogenic neurologic deficit after lumbar spine surgery: a review. Clin Neurol Neurosurg. 2015;139:76-80.

41. Taylor BA, Vaccaro AR, Hilibrand AS, et al. The risk of foraminal violation and nerve root impingement after anterior placement of lumbar interbody fusion cages. Spine (Phila $\mathrm{Pa}$ 1976). 2001;26(1):100-104.

42. Choi K-C, Ahn Y, Kang B-U, et al. Failed anterior lumbar interbody fusion due to incomplete foraminal decompression. Acta Neurochir (Wien). 2011;153(3):567-574.

43. Dickerman R, Zigler J, Sachs B, Rashbaum R. Stretch neuropraxia after anterior lumbar interbody fusion or artificial disc placement. Spine J. 2005;5(4):S8.

44. Kitab SA, Miele VJ, Lavelle WF, Benzel EC. Pathoanatomic basis for stretch-induced lumbar nerve root injury with a review of the literature. Neurosurgery. 2009;65(1):161-168.

45. Mobbs RJ, Parr WCH, Choy WJ, et al. Anterior lumbar interbody fusion using a personalized approach: is custom the future of implants for anterior lumbar interbody fusion surgery? World Neurosurg. 2019;124:452-458.e1.

46. Yaylali I, Ju H, Yoo J, et al. Intraoperative neurophysiological monitoring in anterior lumbar interbody fusion surgery. $J$ Clin Neurophysiol. 2014;31(4):352-355.

\section{Disclosures}

The authors report no conflict of interest concerning the materials or methods used in this study or the findings specified in this paper.

\section{Author Contributions}

Conception and design: Dowlati, Voyadzis. Acquisition of data: Dowlati, Alexander. Analysis and interpretation of data: Dowlati, Alexander. Drafting the article: Dowlati, Alexander. Critically revising the article: Dowlati, Voyadzis. Reviewed submitted version of manuscript: Dowlati. Study supervision: Voyadzis.

\section{Supplemental Information}

\section{Current Affiliations}

Dr. Alexander: Division of Neurosurgery, Ascension Providence Hospital, College of Human Medicine, Michigan State University, Southfield, MI.

\section{Correspondence}

Ehsan Dowlati: Medstar Georgetown University Hospital, Washington, DC. edowlati@gmail.com. 